Article

\title{
Influence of Mo Additions on the Mechanical Properties of Cast Duplex Stainless Steels before and after Thermal Aging
}

\author{
Shilei Li ${ }^{1, *(\mathbb{D} \text {, Yanli Wang }}{ }^{1}$ and Xitao Wang ${ }^{2,3, *(\mathbb{D})}$ \\ 1 State Key Laboratory for Advanced Metals and Materials, University of Science and Technology Beijing, \\ Beijing 100083, China; wangyl@ustb.edu.cn \\ 2 Collaborative Innovation Center of Steel Technology, University of Science and Technology Beijing, \\ Beijing 100083, China \\ 3 Shandong Provincial Key Laboratory for High Strength Lightweight Metallic Materials, Advanced Materials \\ Institute, Qilu University of Technology (Shandong Academy of Science), Jinan 250353, China \\ * Correspondence: lishilei@ustb.edu.cn (S.L.); xtwang@ustb.edu.cn (X.W.); \\ Tel.: +86-135-5272-7287 (S.L.); +86-139-1029-7623 (X.W.)
}

Received: 2 February 2019; Accepted: 26 February 2019; Published: 6 March 2019

\begin{abstract}
The influence of Mo additions on the mechanical properties of cast duplex stainless steel (CDSS) before and after thermal aging was investigated using a series of model alloys with different Mo contents ranging from 0 to $1.75 \mathrm{wt} \%$. By increasing Mo content, the content, morphology, and distribution of ferrite in CDSS change significantly. After thermal aging at $400{ }^{\circ} \mathrm{C}$ for $3000 \mathrm{~h}$, the impact properties of all CDSS specimens obviously decline, and their hardness values in ferrite significantly increase. The impact energies of the aged CDSS decline, and the proportion of cleavage features significantly increases with Mo content increasing. The spinodal decomposition kinetics in ferrite is not significantly affected by the Mo contents. High content and interconnected ferrite will lead to the severe embrittlement in CDSS after thermal aging.
\end{abstract}

Keywords: duplex stainless steels; Mo content; thermal aging; impact; nanoindentation

\section{Introduction}

Cast duplex stainless steel (CDSS) components are widely used in the pressure boundary of primary coolant (i.e., the primary circuit piping and pump casing) of light water reactors. These components have been found to be sensitive to thermal aging embrittlement at service temperatures [1,2]. This embrittlement, called " $475{ }^{\circ} \mathrm{C}$ embrittlement", has been extensively investigated and is widely considered to be caused by the formation of $\mathrm{Cr}$-rich $\left(\alpha^{\prime}\right)$ and $\mathrm{Cr}$-depleted $(\alpha)$ regions by spinodal decomposition in ferrite of CDSS [3-7].

There are two factors that affect the thermal aging behavior of CDSS. One involves the microstructures of ferrite, such as content, morphology, and distribution. It was found that the high content, long shape, and interconnection of the ferrite phases aggravated thermal aging embrittlement [8-10]. The other factor is spinodal decomposition kinetics, which is mainly determined by the composition of ferrite [10-12]. Cr, Ni, and $\mathrm{Mo}$ are the most important elements related to thermal aging embrittlement in CDSS, and they influence both the ferrite microstructure and spinodal decomposition kinetics.

The content of ferrite in CDSS is determined by the ratio of the equivalent $\mathrm{Cr}\left([\mathrm{Cr}]_{\text {eq. }}\right)$ and equivalent $\mathrm{Ni}\left([\mathrm{Ni}]_{\text {eq. }}\right)$, according to the DeLong diagram. As a ferrite former, Mo has the same $[\mathrm{Cr}]_{\text {eq }}$. coefficient as Cr. In addition to increasing ferrite content in CDSS, the addition of the Mo element can appreciably strengthen the solid solution and promote corrosion resistance [13-15]. Increasing $\mathrm{Cr}$ 
content can expand the spinodal decomposition degree of ferrite, and the addition of the Ni element significantly accelerates the kinetics of decomposition in ferrite $[10,16,17]$. Mo was also considered to influence the G-phase precipitation and spinodal decomposition in ferrite of CDSS [18]. The impact property was widely used to evaluate the degree of thermal-aging-induced embrittlement because the impact property of CDSS was much more sensitive to thermal aging embrittlement than other mechanical properties [1,2]. The hardening degree in ferrite of CDSS after thermal aging could be used to assess spinodal decomposition kinetics [8-10].

In this study, we investigated a series of model alloys with different Mo additions. Impact properties and nanohardness in ferrite was used to evaluate the influence of Mo on the ferrite microstructure and spinodal decomposition kinetics in ferrite of CDSS. It is expected to reveal the mechanisms of the influence of Mo on the microstructures and mechanical properties of CDSS before and after thermal aging. The investigation results are helpful to understand and evaluate the thermal aging embrittlement of Mo-free and Mo-bearing CDSS used in reactors and design of the advanced alloys resistant to thermal aging embrittlement.

\section{Materials and Methods}

Model alloys Fe-21Cr-10Ni-0.35Si-xMo with different Mo contents of 0.0, 0.20, 0.90, and $1.75 \mathrm{wt} \%$ (labeled as M0, M1, M2, and M3, respectively) were prepared by arc-melting using elemental ingredients with a purity above $99.9 \mathrm{at} \%$ in a high-purity argon atmosphere. The melted alloys were drop-cast into a water-cooled cast iron mould with dimensions of $\Phi 45 \mathrm{~mm} \times 120 \mathrm{~mm}$. The as-cast alloys were further annealed at $1100^{\circ} \mathrm{C}$ for $20 \mathrm{~h}$ and quenched in water to remove the macrosegregation.

The microstructures in the four model alloys were observed in a Supra 55 (Zeiss, Oberkochen, Germany) scanning electron microscope (SEM) using the backscattered electron imaging (BEI) mode. A JXA 8100 (JEOL, Tokyo, Japan) electron probe microanalyzer (EPMA) was used to detect the compositions of ferrite and austenite in the alloys. Some specimens were thermally aged at $400{ }^{\circ} \mathrm{C}$ for $3000 \mathrm{~h}$ to evaluate their performance after thermal aging. Nanoindentation was employed to investigate the micromechanical properties of ferrite in the alloys before and after thermal aging. The specimens for indentation tests were mechanically polished and then chemically etched to distinguish ferrite from the austenite matrix. The continuous stiffness measurement mode was used with an indentation depth of $500 \mathrm{~nm}$ and more than five indents were tested for each sample. The impact behaviors of the unaged and aged model alloys were tested with an instrumented impact tester using the standard V-notched Charpy specimen dimension. The fracture surfaces of the impact specimens were observed using the previously mentioned SEM. The influence of Mo addition on the spinodal decomposition degree of ferrite in the CDSS was estimated using the JmatPro (Sente Software, Guildford, UK).

\section{Results and Discussions}

\subsection{Influence of Mo Additions on the Microstructures}

\subsubsection{Ferrite Morphology and Content}

Figure 1 shows the SEM-BEI micrographs of the studied CDSS. All four steels show duplex phase structures, in which ferrite distributes in the matrix of austenite. The addition of Mo obviously changes the morphologies of the ferritic and austenitic phases in the CDSS. With an increase of Mo content, the dendrite spacing of austenite decreases, and the average length of ferrite increases. The volume fraction of ferrite was measured with the SEM-BEI micrographs using ImageJ (U. S. National Institutes of Health, Bethesda, MD, USA), and the results are listed in Table 1. The result for each alloy was the average of five measurements using images with a magnification of 100, and the total measured area for each result is approximately $5 \mathrm{~mm}^{2}$. The ferrite content of CDSS increases significantly with an increase in Mo content, from $5.5 \%$ of M0 steel to $23.5 \%$ of M3 steel. The variation of phase fraction with Mo content for a Fe-21Cr-10Ni-0.35Si-xMo alloy at $1100{ }^{\circ} \mathrm{C}$ was calculated using JMatPro. The calculated 
and measured results of ferrite contents in the CDSS with different Mo additions are displayed in Figure 2. With increases in Mo content, the phase fraction of ferrite increases linearly. The calculated results are consistent with the measurements.

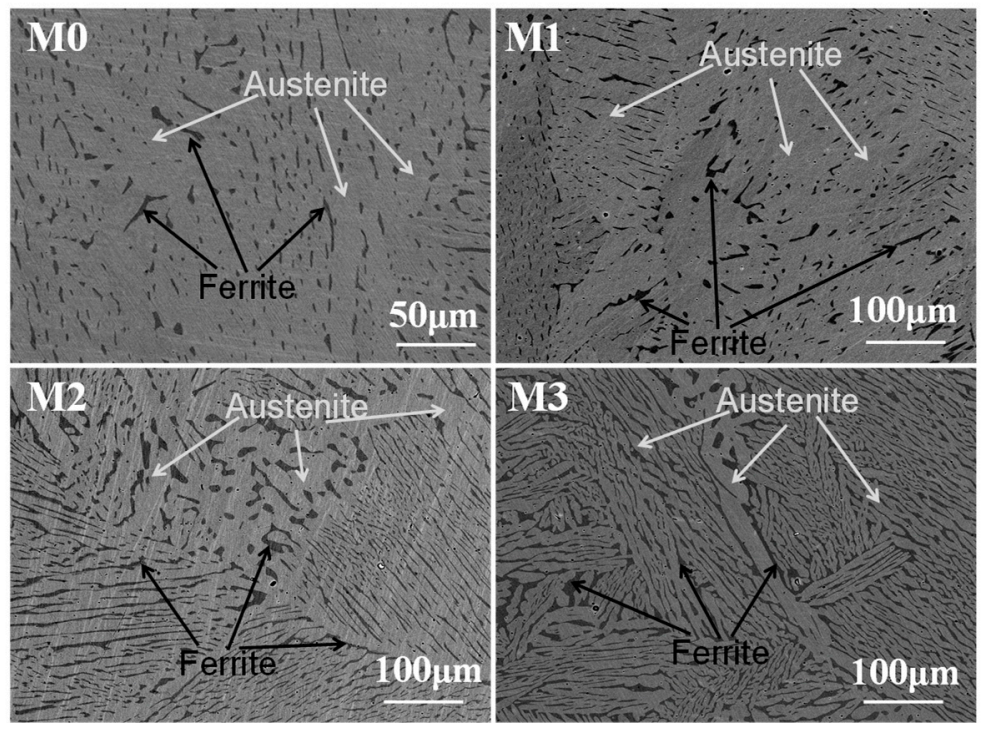

Figure 1. SEM images of the studied model alloys showing their duplex (austenite + ferrite) microstructures. (M0, M1, M2, and M3 corresponds the alloy with Mo content of 0.0, 0.20, 0.90, and $1.75 \mathrm{wt} \%$, respectively.)

Table 1. The ferrite content and compositions in the two phases of CDSS.

\begin{tabular}{cccccccccc}
\hline \multirow{2}{*}{ Material } & \multirow{2}{*}{ Ferrite Content } & \multicolumn{4}{c}{ Ferrite } & \multicolumn{4}{c}{ Austenite } \\
\cline { 3 - 9 } & & $\mathbf{C r}$ & $\mathbf{N i}$ & $\mathbf{S i}$ & $\mathbf{M o}$ & $\mathbf{C r}$ & $\mathbf{N i}$ & Si & Mo \\
\hline M0 & $5.5 \% \pm 0.2 \%$ & 26.49 & 5.81 & 0.38 & - & 20.59 & 9.61 & 0.35 & - \\
M1 & $7.2 \% \pm 0.2 \%$ & 26.79 & 5.68 & 0.39 & 0.29 & 20.92 & 9.46 & 0.37 & 0.19 \\
M2 & $15.1 \% \pm 0.2 \%$ & 26.03 & 5.98 & 0.38 & 1.33 & 20.13 & 9.98 & 0.35 & 0.82 \\
M3 & $23.5 \% \pm 0.3 \%$ & 25.57 & 6.04 & 0.38 & 2.55 & 19.63 & 10.3 & 0.34 & 1.50 \\
\hline
\end{tabular}

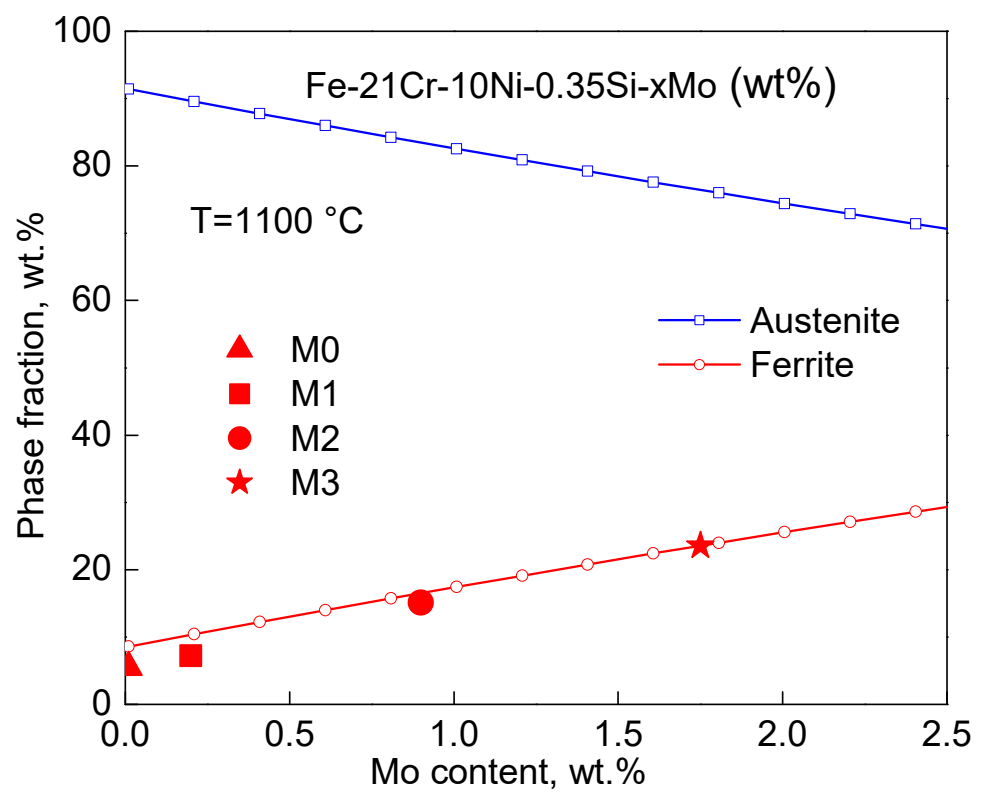

Figure 2. Variation of phase fraction with Mo content for Fe-21Cr-10Ni-0.35Si-xMo alloy, calculated using JMatPro. 
Table 1 also shows the element distribution in ferrite and austenite of CDSS, as measured by EPMA. The ferritic phase is enriched in $\mathrm{Cr}$ and the austenitic phase contains more Ni. As a ferrite-forming element, Mo also concentrates in ferrite. For the compositions of ferrite in M0, M1, M2, and M3 steels, the contents of $\mathrm{Cr}, \mathrm{Ni}$, and $\mathrm{Si}$ are nearly the same, and Mo content varies from 0 to $2.55 \mathrm{wt}$.\%. Therefore, the differences of microstructures and micromechanical in ferrite of CDSS can only be attributed to the influence of Mo content.

\subsubsection{Solidification Mode}

The solidification mode of CDSS depends on the ratio of the equivalent $[\mathrm{Cr}]_{\text {eq. }} /[\mathrm{Ni}]_{\text {eq., }}$ which ranges from 2.15 to 2.40 for the studied four model alloys. This indicates that all these alloys have the same solidification modes for the F mode [19]. The solidification sequence of the F mode is: Liquid $\rightarrow$ Liquid + Ferrite $\rightarrow$ Ferrite $\rightarrow$ Ferrite + Austenite. The equilibrium calculation of the Fe-21Cr-10Ni-0.35Si-xMo alloy at high temperature regions using JmatPro, as shown in Figure 3, proves the above process of microstructure evolution. The typical microstructure of the $\mathrm{F}$ mode solidification is shown in Figure 4, in which the allotriomorphic austenite forms at the prior ferrite grain boundaries and the Widmanstätten austenite needles extend inside the prior ferrite grains.

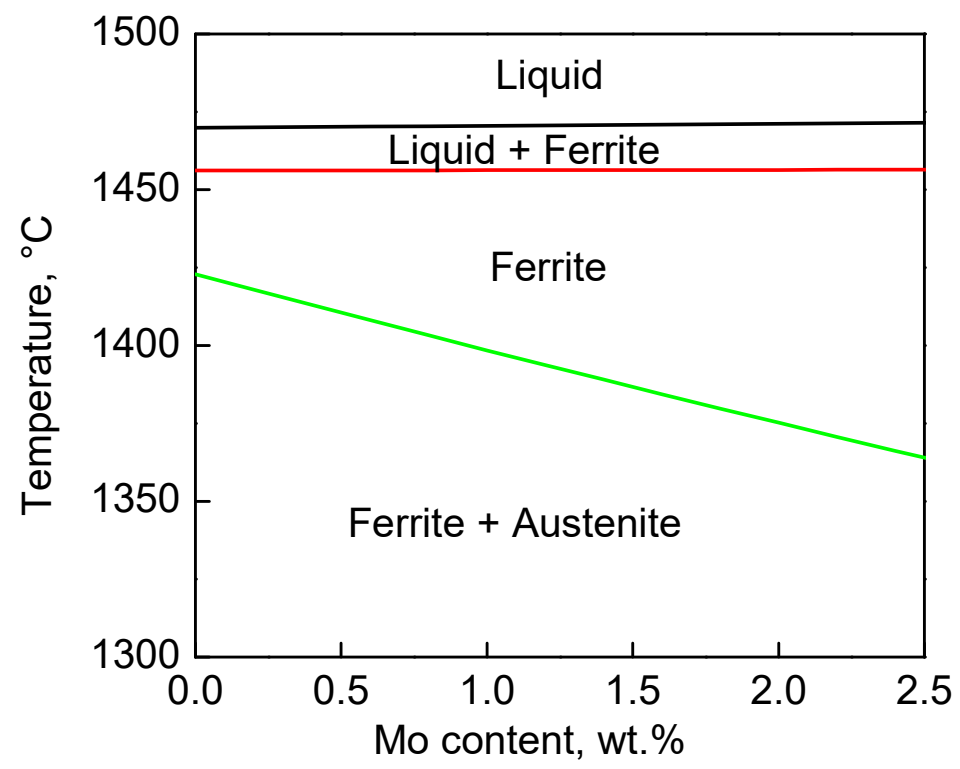

Figure 3. Equilibrium calculation of the Fe-21Cr-10Ni-0.35Si-xMo alloy at high temperature regions.
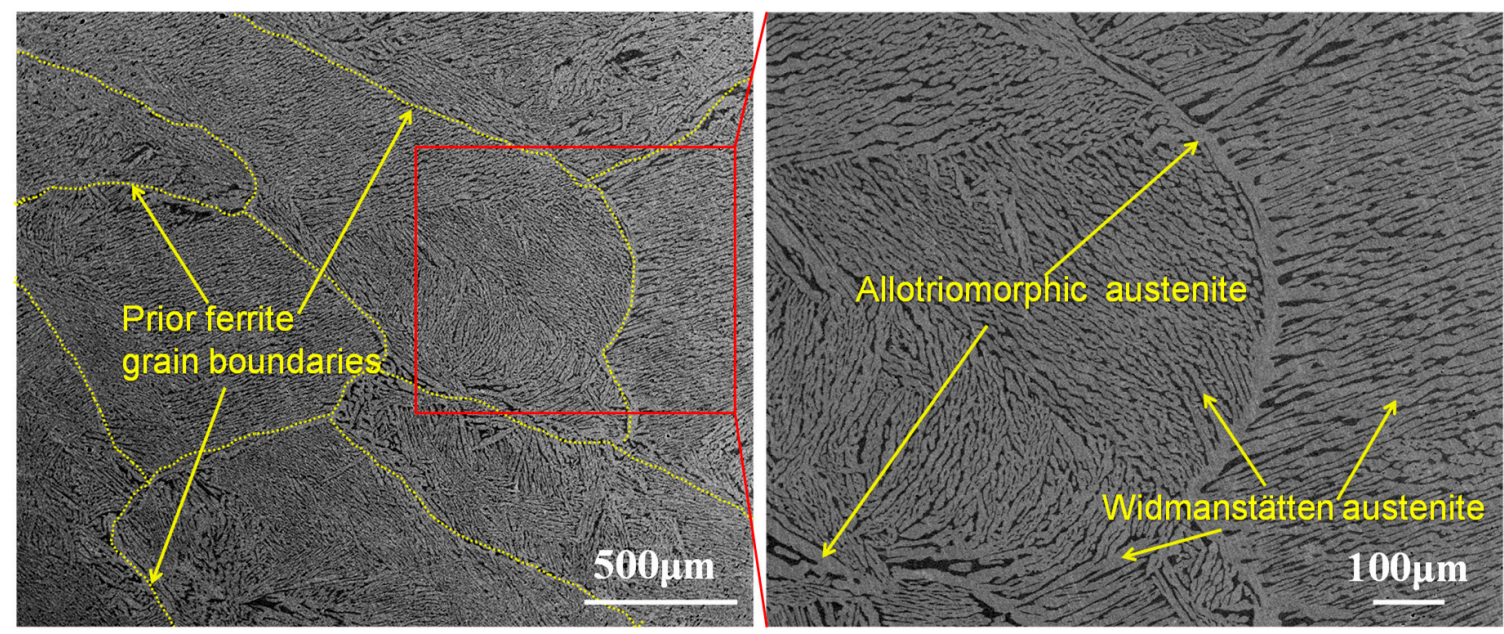

Figure 4. Typical microstructure of the F mode solidification. 


\subsection{Influence of Mo Additions on Mechanical Properties}

\subsubsection{Impact Properties}

The force-displacement curves of impact specimens with different Mo additions are shown in Figure 5. The area enclosed by the curve and displacement axis is the total impact energy. With Mo content increasing from 0 to $1.75 \mathrm{wt} \%$, the impact energies of the unaged CDSS show no significant change. The impact fracture morphologies of the unaged steels are shown in Figure 6. All of them exhibit ductile fracture features with dimples in both ferrite and austenite. The dimple sizes on the fracture surfaces become larger with increasing Mo content.

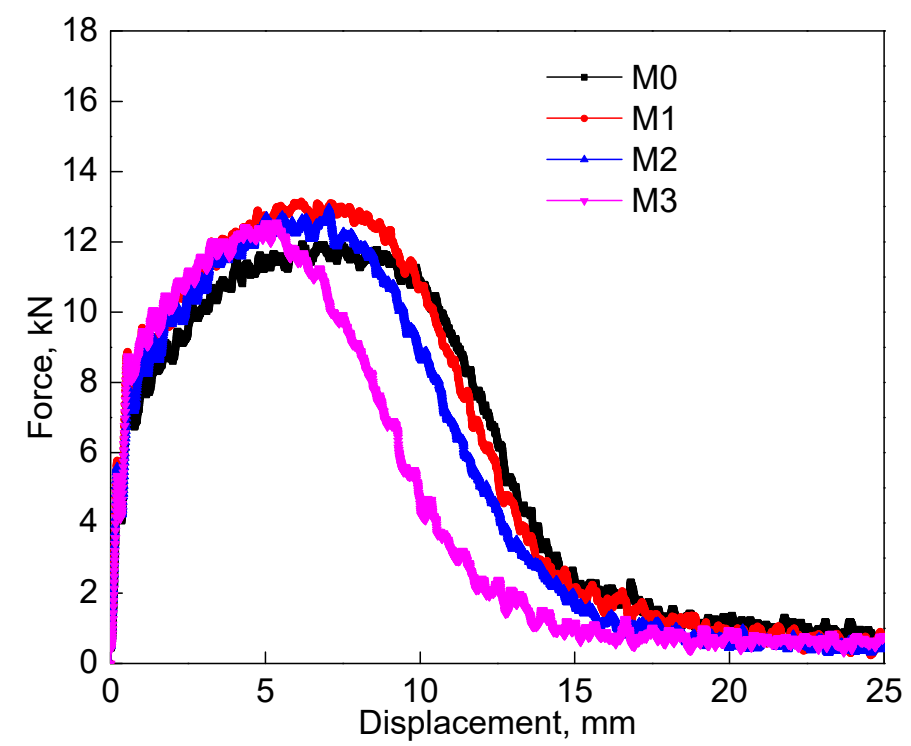

Figure 5. Force-displacement curves of impact specimens with different Mo additions.

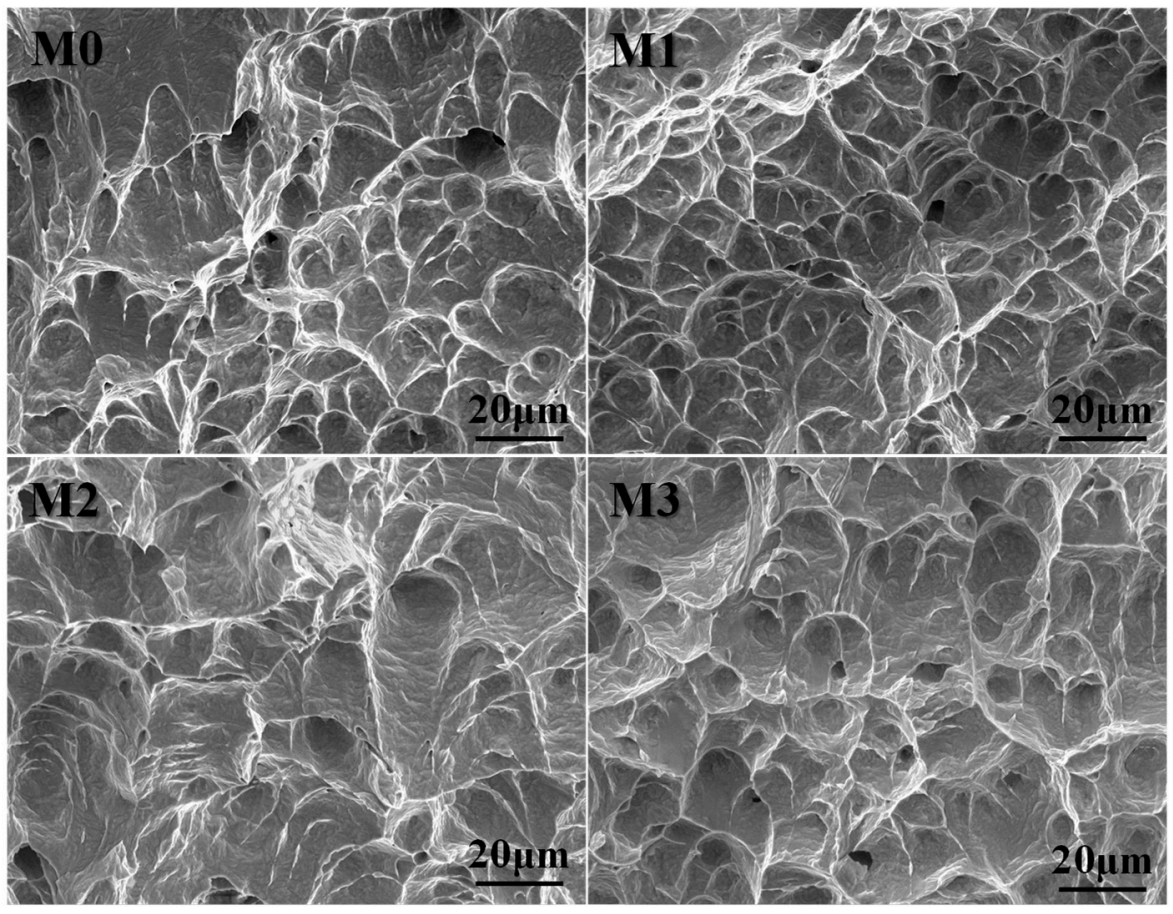

Figure 6. Morphologies of the fracture surfaces of the unaged cast duplex stainless steel (CDSS) specimens. (M0, M1, M2, and M3 corresponds the alloy with Mo content of 0.0, 0.20, 0.90, and $1.75 \mathrm{wt} \%$, respectively.) 


\subsubsection{Micromechanical Properties}

The micromechanical properties in both ferrite and austenite were investigated using the nanoindentation technique. Figure 7 shows the nanohardness results of the unaged CDSS with different Mo additions. For all the unaged specimens, ferrite has a slight higher hardness than austenite. The hardness of ferrite and austenite in the unaged CDSS is not obviously influenced by increasing Mo content.

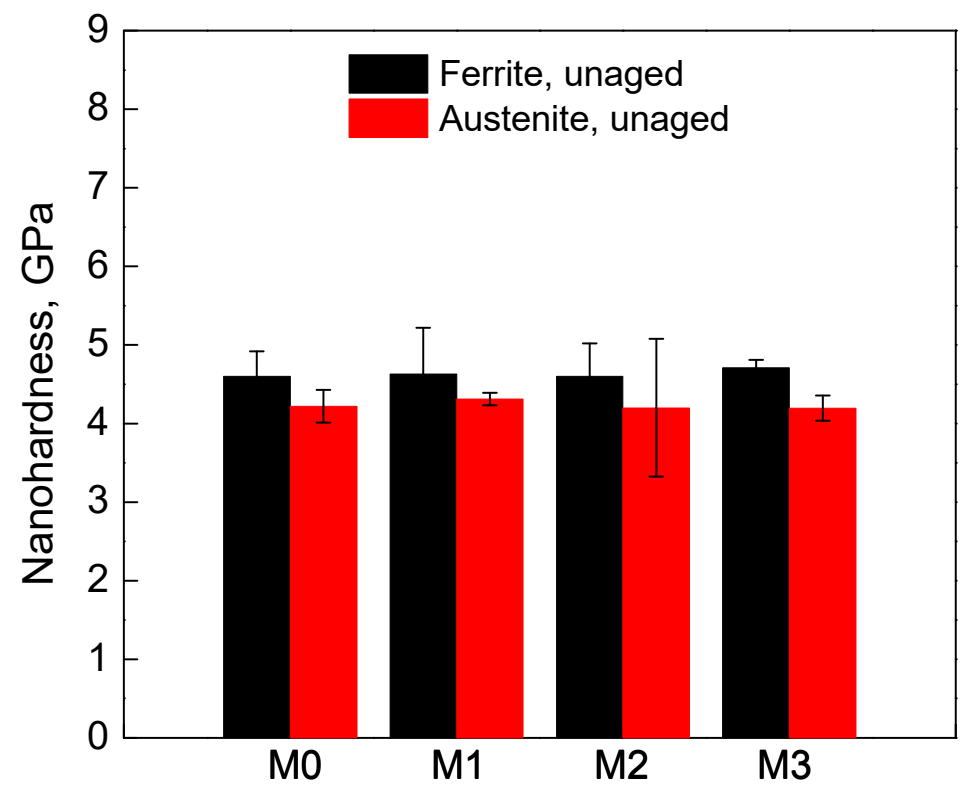

Figure 7. Nanohardness of ferrite and austenite in the unaged CDSS specimens.

\subsection{Mechanical Property Changes After Thermal Aging}

\subsubsection{Changes of Impact Property}

The CDSS specimens with different Mo additions were thermally aged at $400{ }^{\circ} \mathrm{C}$ for 100,1000 , and $3000 \mathrm{~h}$, and their impact properties after thermal aging were investigated. Figure 8 shows the variation of impact energies, with Mo additions at different thermal aging states. With an increase in Mo content, the impact energies of the aged CDSS decline to different extents. After thermal aging at $400{ }^{\circ} \mathrm{C}$ for $3000 \mathrm{~h}$, the impact energies of M0, M1, M2, and M3 steels decrease by $17.0 \%, 27.6 \%, 33.9 \%$, and $52.2 \%$, respectively. The addition of Mo element accelerates the rate of thermal aging embrittlement in CDSS.

Figure 9 shows the morphologies of the impact fracture surfaces of the CDSS specimens aged at $400{ }^{\circ} \mathrm{C}$ for $3000 \mathrm{~h}$. Compared with the unaged materials, the fracture surfaces of the aged CDSS become flatter. The features of austenite on the fracture surface are displayed as dimples, which also get larger and shallower with increasing Mo content. A cleavage fracture of ferrite was observed in M1, M2, and M3 after thermal aging; the cleavage facets on the impact fracture are marked in red in Figure 6 . The proportion of cleavage features significantly increases with increasing Mo content. The amounts of ferrite on the fracture surfaces of the aged M0, M1, and M2 specimens are lower than their average ferrite contents. The fraction of cleavage facets on the fracture surface of the aged M3 steel is higher than its ferrite content; this phenomenon is thought to be caused by the morphology and distribution of ferrite. The long-strip shaped and interconnected ferrite island make the primary crack propagate along a larger cleavage facet. High content and interconnected ferrite will lead to severe embrittlement in CDSS after thermal aging. 


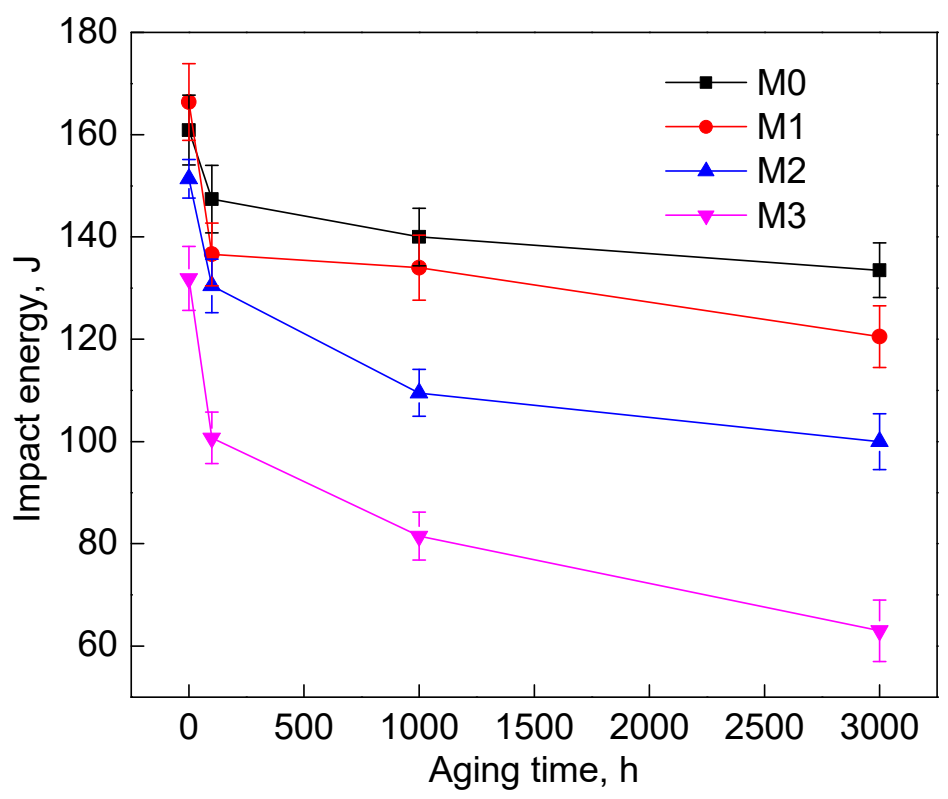

Figure 8. Variation of the impact energies of M0, M1, M2, and M3 steels with aging time.
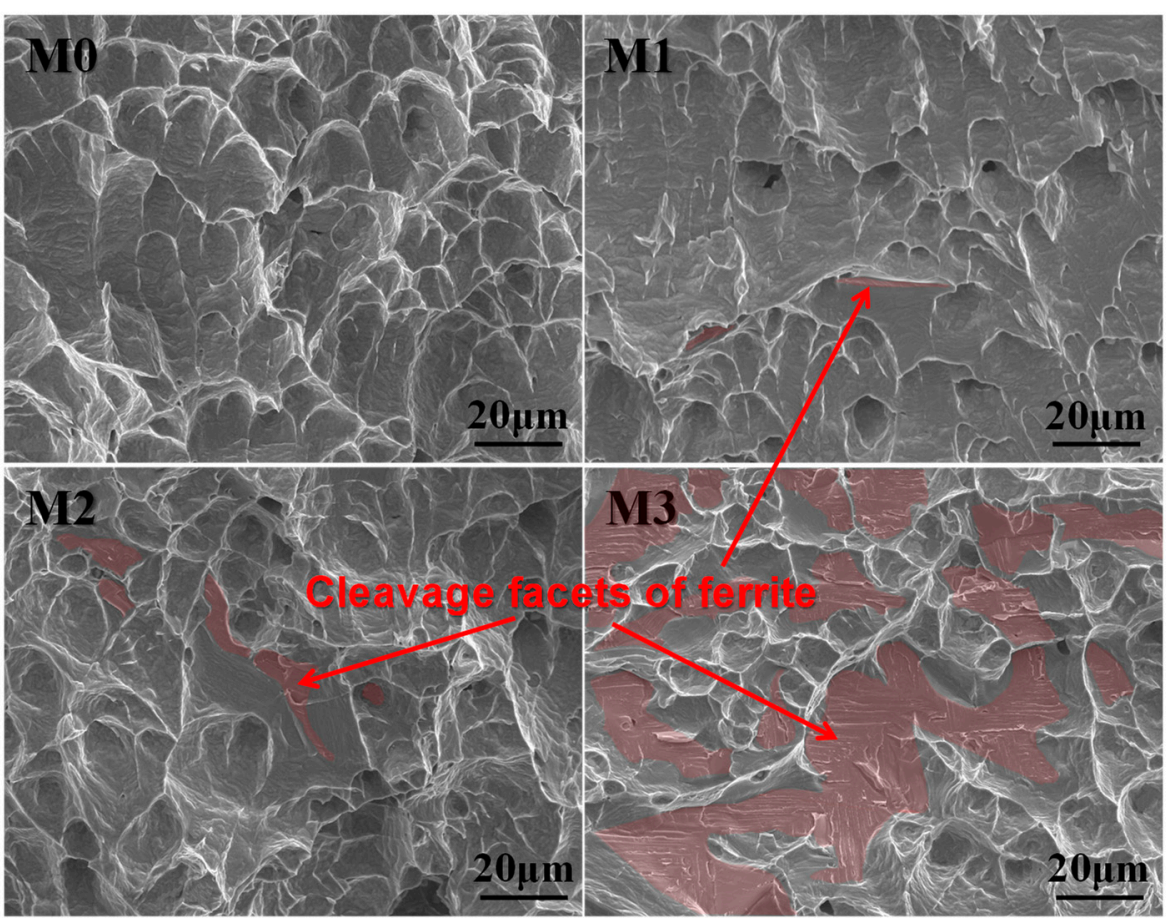

Figure 9. Morphologies of the impact fracture surfaces of the CDSS specimens thermally aged at $400{ }^{\circ} \mathrm{C}$ for $3000 \mathrm{~h}$. (M0, M1, M2, and M3 corresponds the alloy with Mo content of 0.0, 0.20, 0.90, and $1.75 \mathrm{wt} \%$, respectively.).

\subsubsection{Changes of Micromechanical Properties}

Figure 10 shows the nanohardness of ferrite and austenite in the aged CDSS. The hardness values in austenite are nearly the same, while the hardness values of ferrite in the M0, M1, M2, and M3 steels almost doubled after thermal aging at $400{ }^{\circ} \mathrm{C}$ for $3000 \mathrm{~h}$. Thermal aging only affected the micromechanical properties of ferrite. This hardening was caused by the spinodal decomposition of the ferrite during thermal aging. The hardness of ferrite in the aged CDSS was not significantly affected by the Mo contents. 


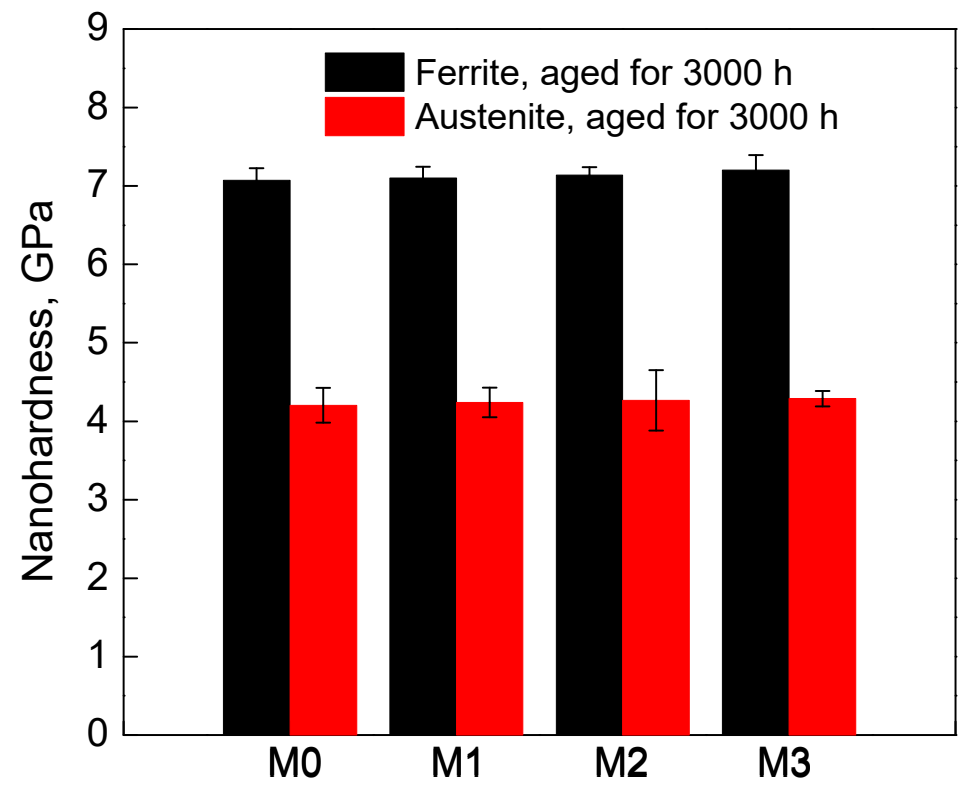

Figure 10. Nanohardness of ferrite and austenite in the aged CDSS specimens.

For the unaged M0, M1, M2, and M3 steels, both the ferritic and austenitic phases have similar hardness and good plasticity, resulting in their good impact properties and ductile fracture features. After thermal aging, the ferritic phase became hardened and embrittled because of spinodal decomposition. The decrease in the deformation ability of ferrite in the aged steels lead to the increase of deformation resistance under impact loading. M3 steel has coarse ferrite grains, which may interconnect with each other in space. Once the cleavage cracks initiate in ferrite of the aged M3 steel, they will quickly propagate through the whole ferrite grain. As M0, M1, and M2 steels have lower content and smaller sizes of ferrite, their fracture processes are weakly affected by thermal aging.

\section{Conclusions}

The effects of Mo content on the microstructure and mechanical properties of CDSS before and after thermal aging were investigated in this study, and the conclusions can be summarized as follows:

The addition of Mo obviously changes the morphologies of the ferritic and austenitic phases in the CDSS. The dendrite spacing of austenite decreases and the average length and volume fraction of ferrite increases with an increase in Mo content. The impact properties and hardness in the unaged CDSS is not obviously influenced by an increase in Mo content. After thermal aging at $400{ }^{\circ} \mathrm{C}$ for $3000 \mathrm{~h}$, the impact energies of the CDSS were reduced by up to $52.2 \%$, and the hardness values of the ferrite were double those of the unaged. When Mo content increases, the impact energies of the aged CDSS decline, and the proportion of cleavage features significantly increases. The kinetics of spinodal decomposition in ferrite induced by thermal aging are not significantly affected by the addition of Mo less than $2 \mathrm{wt} \%$. High content and interconnected ferrite will lead to severe embrittlement in the CDSS after thermal aging. The investigation results are helpful to understand and evaluate the thermal aging embrittlement of Mo-free and Mo-bearing CDSS used in reactors and to design advanced alloys resistant to thermal aging embrittlement.

Author Contributions: X.W. and Y.W. designed the research project; S.L. performed the experiments, analyzed the data and wrote the manuscript; all the authors contributed to the discussions and comments on the manuscript.

Funding: This work was financially supported by the National Natural Science Foundation of China (NSFC) (Grant No. 51601013) and the State Key Laboratory for Advanced Metals and Materials (Grant No. 2018Z-25).

Conflicts of Interest: The authors declare no conflict of interest. 


\section{References}

1. Chung, H.M.; Leax, T.R. Embrittlement of laboratory and reactor aged CF3, CF8, and CF8M duplex stainless steels. Mater. Sci. Tech. 2013, 6, 249-262. [CrossRef]

2. Hale, G.E.; Garwood, S.J. Effect of aging on fracture behaviour of cast stainless steel and weldments. Mater. Sci. Tech. 1990, 6, 230-236. [CrossRef]

3. Brown, J.E.; Cerezo, A.; Godfrey, T.J.; Hetherington, M.G.; Smith, G.D.W. Quantitative atom probe analysis of spinodal reaction in ferrite phase of duplex stainless steel. Mater. Sci. Tech. 1990, 6, 293-300. [CrossRef]

4. Miller, M.K.; Hyde, J.M.; Hetherington, M.G.; Cerezo, A.; Smith, G.D.W.; Elliott, C.M. Spinodal decomposition in Fe-Cr alloys: Experimental study at the atomic level and comparison with computer models-I. Introduction and methodology. Acta Metall. Mater. 1995, 43, 3385-3401. [CrossRef]

5. Hyde, J.M.; Miller, M.K.; Hetherington, M.G.; Cerezo, A.; Smith, G.D.W.; Elliott, C.M. Spinodal decomposition in Fe-Cr alloys: Experimental study at the atomic level and comparison with computer models-II. Development of domain size and composition amplitude. Acta Metall. Mater. 1995, 43, 3403-3413. [CrossRef]

6. Hyde, J.M.; Miller, M.K.; Hetherington, M.G.; Cerezo, A.; Smith, G.D.W.; Elliott, C.M. Spinodal decomposition in Fe-Cr alloys: Experimental study at the atomic level and comparison with computer models-III. Development of morphology. Acta Metall. Mater. 1995, 43, 3415-3426. [CrossRef]

7. Xiong, W.; Selleby, M.; Chen, Q.; Odqvist, J.; Du, Y. Phase equilibria and thermodynamic properties in the Fe-Cr system. Crit. Rev. Solid State 2010, 35, 125-152. [CrossRef]

8. Li, S.; Wang, Y.; Wang, X. Effects of ferrite content on the mechanical properties of thermal aged duplex stainless steels. Mater. Sci. Eng. A 2015, 625, 186-193. [CrossRef]

9. Li, S.; Wang, Y.; Zhang, H.; Li, S.; Wang, G.; Wang, X. Effects of prior solution treatment on thermal aging behavior of duplex stainless steels. J. Nucl. Mater. 2013, 441, 337-342. [CrossRef]

10. Li, S.; Wang, Y.; Wang, X. Effects of Ni content on the microstructures, mechanical properties and thermal aging embrittlement behaviors of Fe-20Cr- $x$ Ni alloys. Mater. Sci. Eng. A 2015, 639, 640-646. [CrossRef]

11. Hyde, J.M.; Miller, M.K.; Cerezo, A.; Smith, G.D.W. A study of the effect of ageing temperature on phase separation in Fe-45\%Cr alloys. Appl. Surf. Sci. 1995, 87, 311-317. [CrossRef]

12. Soriano-Vargas, O.; Avila-Davila, E.O.; Lopez-Hirata, V.M.; Cayetano-Castro, N.; Gonzalez-Velazquez, J.L. Effect of spinodal decomposition on the mechanical behavior of Fe-Cr alloys. Mater. Sci. Eng. A 2010, 527, 2910-2914. [CrossRef]

13. Anderson, T.D.; Dupont, J.N.; Perricone, M.J.; Marder, A.R. Phase transformations and microstructural evolution of Mo-Bearing stainless steels. Metall. Mater. Trans. A 2007, 38, 86-99. [CrossRef]

14. Wang, K.; Chang, B.; Chen, J.; Fu, H.; Lin, Y.; Lei, Y. Effect of molybdenum on the microstructures and properties of stainless steel coatings by laser cladding. Appl. Sci. 2017, 7, 1065. [CrossRef]

15. Wang, M.J.; Long, S.S.; Mu, S.M.; Wang, Y.; Chen, L. Effect of molybdenum on hot deformation and processing maps of austenitic stainless steels. Mater. Sci. Forum 2008, 575-578, 1076-1082. [CrossRef]

16. Miller, M.K.; Anderson, I.M.; Bentley, J.; Russell, K.F. Phase separation in the Fe-Cr-Ni system. Appl. Surf. Sci. 1996, 94, 391-397. [CrossRef]

17. Miller, M.K.; Hyde, J.M.; Cerezo, A.; Smith, G.D.W. Comparison of low temperature decomposition in Fe-Cr and duplex stainless steels. Appl. Surf. Sci. 1995, 87, 323-328. [CrossRef]

18. Danoix, F.; Auger, P. Atom probe studies of the Fe-Cr system and stainless steels aged at intermediate temperature: A review. Mater. Charact. 2000, 44, 177-201. [CrossRef]

19. Feng, Y.; Luo, Z.; Liu, Z.; Li, Y.; Luo, Y.; Huang, Y. Keyhole gas tungsten arc welding of AISI 316L stainless steel. Mater. Des. 2015, 85, 24-31. [CrossRef]

(C) 2019 by the authors. Licensee MDPI, Basel, Switzerland. This article is an open access article distributed under the terms and conditions of the Creative Commons Attribution (CC BY) license (http:/ / creativecommons.org/licenses/by/4.0/). 